\title{
ВОПРОСЫ РЕФОРМИРОВАНИЯ СИСТЕМЫ ГОСУДАРСТВЕННОГО ПЛАНИРОВАНИЯ В РЕСПУБЛИКЕ КАЗАХСТАН*
}

\author{
Гульсара Джунусбекова \\ Академия государственного управления \\ при Президенте Республики Казахстан, \\ Астана,Республика Казахстан, ул. Абая 33 «а» \\ doi:10.13165/VPA-13-12-4-08
}

\begin{abstract}
Аннотация. В статье анализируется опьт реформирования системь государственного планирования в Республике Казахстан. Рассматривается ряд системных проблем в сфере государственного стратегического планирования. В настоящее время в Казахстане сформирована институциональная база системь государственного планирования. Однако на практике имеют место проблемь по взаимосвязке целей и задач государственных органов с бюджетированием, обеспечения полной декомпозиции показателей и другие. Для решения этих и других проблем на системной основе выявляется необходимость проведения исследований в данном направлении.
\end{abstract}

Keywords: system of state planning, strategic planning, evaluation.

Ключевые слова: система государственного планирования, стратегическое планирование, оценка.

\section{Введение}

В Казахстане на решение задачи акцентирования внимания на необходимости улучшения качества жизни наших граждан направлены приоритетные национальные проекты, проводится реформа системы государственного управления, стратегические цели государства связаны с улучшением качества жизни.

* This article is part of the electronic conference: „Public Administration in Central Europe: In Search of Tradition" organized by the Institute of Public Administration at Mykolas Romeris University (Vilnius, Lithuania) in partnership with the Academic Association of Management and Administration (Lithuania) on November 6th and 7th, 2013. 
В своем Послании народу Казахстана от 6 февраля 2008 года Президент страны Н.Назарбаев в числе приоритетов выделил ускоренную реализацию мер «по развитию системы государственного управления на принципах результативности». В частности, перед Правительством РК ставится задача «форсировать работу по модернизации и совершенствованию системы планирования и повышению эффективности использования средств бюджета». В рамках реализации административной реформы в Республике Казахстан осуществляется переход на систему государственного управления по результатам.

Внедрение новой модели системы государственного планирования в Республике Казахстан осуществлялось в следующей последовательности:

1) 2007 год. Разработка стратегических планов на период 2008-2010 годы тремя пилотными министерствами (министерства юстиции, финансов, экономики и бюджетного планирования) и двумя управлениями (образования и здравоохранения) региона;

2) Принятие Концепции по внедрению системы государственного планирования, ориентированного на результат (Постановление Правительства РК от 26 декабря 2007 года, № 1297).

3) 2008-2009 годы. Внедрение элементов системы государственного планирования и бюджетирования, ориентированных на результаты, в центральных государственных органах и местных исполнительных органах.

4) Разработка и принятие Бюджетного кодекса Республики Казахстан от 4 декабря 2008 года.

5) Утверждение Указа Президента РК «О системе государственного планирования в Республике Казахстан» от 18.06.2009 г., №827.

6) 2009-2010 годы. Разработка и принятие стратегических и программных документов в соответствии с Указом Президента РК «О системе государственного планирования в Республике Казахстан» от 18.06.2009 г., №827.

Следующим важным этапом при внедрении новой модели государственного планирования было принятие Указа Президента РК «О системе государственного планирования в РК» от 18 июня 2009 года №827. После выхода Указа местные исполнительные органы разработали свои стратегические планы, а центральные государственные органы дорабатывали на пятилетний период (2010-2014 годы). Соответствующие стратегические и программные документы, разрабатываемые в реализацию Стратегического плана развития страны до 2020 года, согласно комплексному плану мероприятий утверждаются по мере их разработки. Система государственного планирования определена как комплекс взаимосвязанных элементов, состоящих из принципов, документов, процессов и участников государственного планирования, обеспечивающий развитие страны на долгосрочный (свыше 5 лет), среднесрочный (от года до 5 лет) и краткосрочный (до года) периоды [1]. 
Государственное планирование необходимо и потому, что государство формирует ряд стратегических заказов, для реализации которых требуется запуск многочисленных стратегических проектов и программ. Большая часть из них носит долгосрочный перспективный характер, их отличительная особенность - сложный механизм координации и системные связи друг с другом, которые требуют точной синхронизации во времени. В этой связи возникла необходимость формирования целостной системы государственного планирования, которое включают различное множество программных документов и ключевых показателей эффективности, которые не всегда взаимоувязаны между собой и инструментами системы стратегического планирования.

Таким образом, на современном этапе модернизации государственного управления выявляется необходимость научного анализа процессов становления и развития системы государственного планирования Республики Казахстан, осмысления сути происходящих перемен и потребности в научно - обоснованных рекомендациях по реформированию и совершенствованию системы государственного планирования.

Методологией данного исследования выступили тематические исследования, наблюдение и анализ документов, формализация и системный подход.

\section{Теоретические аспекты исследования стратегического планирования в государственном управлении}

В настоящее время уровень исследования стратегического планирования в государственном управлении и оценки стратегических планов государственных органов в Казахстане является актуальным вопросом, требующего более детального изучения. В современной экономической литературе этот вопрос разработан более продуктивно в развитых зарубежных странах.

Анализу места, роли и значения стратегического планирования в эффективном функционировании различных сфер системы государственного управления посвящены работы П. Мизинга, Дэвида Ф. Андерсена [2], И. О. Угборо, К. Обенга, О. Спэн [3], Т. Поистера [4], М. Барзлай, К. Кэмпбелла [5], Дж. М. Брайсона [6], Дж. М. Брайсона, Б. С. Кросби, и Дж К. Брайсона [7], У. Ю. Френцель, Дж. М. Брайсона, Б. С. Кросби [8], и других.

Следует отметить, что различные подходы, методология стратегического планирования и практика в системе государственного управления, были заимствованы с коммерческого сектора.

Анализ функционирования стратегического государственного планирования в зарубежных странах $[2,3,4,5,6,7,8]$ свидетельствует, что система неразрывно связана с бюджетированием для определения результативности и эффективности использования государственных средств:

- Особенностью стратегических планов является то, что они служат осно- 
вой для измерения социальной эффективности достигнутых результатов. Для этого в стратегический план включается соотношение долгосрочных и краткосрочных (установленных на год) целей и целевые значения социальной эффективности программ на планируемый период.

- Современная система стратегического планирования в развитых зарубежных странах выстраивается исходя из принципов каскадирования целей и задач от стратегических направлений деятельности Администраций Президентов либо правительств до отражения (каскадирования) в стратегических планах министерств, ведомств, департаментов и далее формулирования в их стратегических целях.

- Внедрение бюджетирования, ориентированного на результат, связано прежде всего со смещением внимания с детализированных статьей расходов к распределению ресурсов на основе программных целей и измеряемых результатов. При этом основой для определения параметров целевых значений показателей стратегического плана служат выделенные для их реализации лимиты бюджетных ассигнований Правительств.

Многие зарубежные страны достигли значительных результатов в области стратегического планирования в условиях рыночной экономики. Казахстан изучал опыт многих стран, при этом следует понимать, что невозможно перенести и использовать зарубежный опыт без соответствующих корректировок, учитывающих специфические особенности нашего государства.

Традиционно в мире выделяют две основные модели планирования. Одна их которых, англосаксонская модель, которая во главу угла ставит бюджетное планирование, а все остальные планы выполняют в большей мере вспомогательную роль. К числу наиболее ярких представителей подобной модели относят США, и Великобританию. Вторая модель предполагает наличие строго организованной системы государственных органов планирования. Приоритетом их деятельности является разработка планов (прогнозов) развития страны, отдельных регионов и отраслей на различные сроки. Страны, использующие подобную модель, - Индия, Япония, Южная Корея, Китай, латиноамериканские страны и др.

Для США характерно стратегическое планирование, суть которого состоит в выборе главных приоритетов развития национальной экономики. Опыт США в области планирования содержит перспективные для потенциального внедрения в сферу отечественного планирования аспекты, которые будут способствовать развитию данной отрасли в нашей стране. Сюда следует отнести: формирование и наличие коммерческой отрасли планирования, активное привлечение для разработки моделей экономического развития высших учебных заведений, подготовка высококвалифицированных кадров, а также выстраивание всех отношений между организациями, занимающимися построением планов и органами государственной власти на коммерческой основе. Из бюджетов всех уровней выделяются существенные суммы для финансирования деятельности в области планирования. 
В этом плане интересен опыт общегосударственного планирования в условиях рынка, накопленный во Франции. Французская система оказала стимулирующее влияние на развитие макропланирования в Германии и Великобритании, а в последнее время ее принципы все более пристально изучаются и используются органами межгосударственного регулирования Европейского союза.

С методологической точки зрения Великобритания накопила обширный опыт в построении эконометрических моделей. Таким образом, опыт Великобритании в области планирования имеет ряд существенных особенностей. Основное внимание уделяется стратегиям развития (долгосрочным и краткосрочным).

Особенность стратегического планирования в Японии заключается в использовании системы социально-экономических планов и научно- технических программ как инструмента правительственного регулирования рыночной экономики. Планы развития воплощаются в рамках планов-программ. Все планы строятся на основании статистической информации, проводится глубокий научный анализ. Отличительной особенностью стратегического планирования в Японии является их адаптивность. Система планирования в Японии содержит долгосрочные, среднесрочные и краткосрочные планирования. Краткосрочное планирование в основном используется в бюджетном процессе. Таким образом, опыт Японии может быть достаточно эффективно использован в системе стратегического планирования. Bce планы развития разрабатываются исключительно для практического использования, как государственными служащими, так и частными компаниями. Достаточно успешно зарекомендовал себя опыт привлечения частных компаний для построения различного рода планов. Свою эффективность доказало общественное обсуждение разработанных планов развития, что влияет на результативность данных планов.

Еще одна страна, чей опыт в этой сфере заслуживает внимания, - Финляндия. Ее уникальный опыт в сферах образования, здравоохранения, социальной защиты, науки и технологий сейчас активно изучается. Наиболее подходящие аспекты системымогут быть внедрены в стратегические планы и программы государственных органов в Казахстане.

Подводя итоги анализа зарубежного опыта в области стратегического планирования, следует выделить ряд ключевых моментов. Для достижения положительных результатов в социально-экономической сфере требуется значительное внимание уделять планированию. В качестве примера можно привести бурное развитие экономик Китая и Индии в наши дни. В Китае и Индии есть специальные органы планирования, наделенные обширными полномочиями и имеющие достаточные финансовые ресурсы. В современных условиях представляется целесообразным использование опыта этих стран для формирования новой организационной структуры органов планирования в Казахстане. Несомненными атрибутами современной системы органов планирования, как на местном уровне, так и на государственном должны стать: строгая организационная структура; широкий круг полномочий соответствующих органов; четкое законодательное 
определение прав, обязанностей и ответственности, а также надлежащие финансирование. Практически все зарубежные страны, в которых существенное внимание уделяется стратегическому планированию, активно привлекают различные научные организации, университеты и частный сектор. Лидерство в этом аспекте принадлежит США. Все взаимоотношения между государством и подобными организациями выстраиваются на экономической основе.

Зарубежный опыт в области стратегического планирования может быть весьма полезен в системе планирования Казахстана $[9,10,11,12]$.

Во многих развитых странах мира разворачиваются острые дискуссии по вопросу о том, что должно являться объектом государственного планирования: обеспечение национальной безопасности или развитие страны, прежде всего ее экономики и социальной сферы. Государственное планирование необходимо и потому, что государство формирует ряд стратегических заказов, для реализации которых требуется запуск многочисленных стратегических проектов и программ. Большая часть из них носит долгосрочный перспективный характер, их отличительная особенность - сложный механизм координации и системные связи друг с другом, которые требуют точной синхронизации во времени. В этой связи возникла необходимость формирования целостной системы государственного планирования, которое включают различное множество программных документов и ключевых показателей эффективности, которые не всегда взаимоувязаны между собой и инструментами системы стратегического планирования.

Функционирование системы государственного планирования предполагает декомпозицию глобальных целей развития страны и ее долгосрочных приоритетов в конкретные задачи и измеримые показатели для каждого государственного органа. При этом, достижение поставленных целей невозможно без мониторинга процессов и оценки результатов деятельности государственных органов.

В этом свете основным инструментом измерения эффективности и результативности государственных структур призван стать институт оценки эффективности деятельности государственных органов, позволяющий определить степень достижения стратегических целей, качество предоставляемых бизнесу и населению государственных услуг, эффективность использования бюджетных средств.

\section{Анализ опыта формирования государственного стратегического планирования в Республике Казахстан}

Внедрение в 2009 году новой Системы государственного планирования Республики Казахстан позволило выстроить достаточно сбалансированную и целостную систему стратегических и программных документов страны, определить иерархию программных документов в зависимости от их статуса и периода действия, новые подходы к разработке и содержанию стратегических планов государственных органов [1]. 
Система государственного планирования тесно связана с реализацией Стратегического плана - 2020, которое было создано на основе Послания Президента Республики Казахстан народу о стратегическом видении страны до 2020 года.

Основной задачей системы государственного планирования является обеспечение в полной мере эффективного исполнения Стратегического плана 2020, и всех других стратегических и программных документов.

Особенностью стратегического планирования является то, что каждый государственный орган работает на основе своего стратегического плана и несет прямую ответственность за достижение конкретных показателей и индикаторов, которые прямо связаны с целями основных документов страны - Стратегического плана - 2020, государственных программ. Данная система дает возможность четко отследить результативность работы каждого государственного органа и его руководителя. Более того, выделение бюджетных ресурсов государственным органам производится только на цели, изложенные в стратегическом плане, что создает реальные условия и предпосылки для консолидации стратегического, бюджетного, социально-экономического планирования.

До 2013 года основным документом, на который опиралась и направлена вся система государственного планирования в Казахстане является стратегия развития «Казахстан-2030», принятая в 1997 году, в котором был обозначен долгосрочный путь развития страны, направленный на трансформацию страны в одно из самых безопасных, стабильных, устойчивых государств мира с динамично развивающейся экономикой.

В конце 2013 года Президент страны озвучил Стратегию развития до 2050 года. Таким образом, теперь система государственного планирования в РК будет опираться на долгосрочные приоритеты, определенные в данной Стратегии.

В настоящее время долгосрочные приоритеты, заложенные в Стратегии «Казахстан-2050»: новый политический курс состоявшегося государства» конкретизируются в нижестоящих документах системы государственного планирования по иерархии.

Анализ казахстанского опыта стратегического планирования показал, что до сих пор многие программные документы страдают рядом недостатков.

Прежде всего, цели, задачи и ожидаемые результаты многих программ сформулированы размыто, без четких критериев и индикаторов оценки конечных результатов расходования государственных средств на решение задач, вытекающих из программных документов.

По-прежнему, при разработке как плановых, так и программных документов важные приоритеты государственной политики остаются без финансового обеспечения, что заметно снижает роль и место плановых документов в решении актуальных проблем общества, поскольку многие из них остаются на уровне простых декларации из-за отсутствия финансовых ресурсов.

До тех пор пока стратегические приоритеты не будут подкреплены реальными финансовыми ресурсами о повышении роли плановых документов в обществе не 
может быть речи. Поэтому сами процедуры разработки программных документов должны перетерпеть определенные изменения в соответствии с требованиями БОР и разработки стратегических планов министерств и ведомств.

В 2010 году в Республике Казахстан Указом Главы государства № 954 была внедрена Система ежегодной оценки эффективности деятельности центральных государственных и местных исполнительных органов [13].

В этом плане уполномоченным на оценку государственным органом по направлению «Достижение и реализация стратегических целей и задач в курируемых отрасли/сфере/регионе» была разработана соответствующая методика [14]. По итогам оценки прошлых лет методологическая база была доработана, в том числе с учетом рекомендаций международных экспертов в области оценки.

На основании проведенного анализа результатов оценки по данному направлению позволили выявить ряд системных проблем в сфере стратегического планирования. В настоящее время многие программные документы не содержат индикаторы эффективности в виду того, что, как было отмечено выше, многие приоритеты попросту не обеспечены финансовыми ресурсами, поэтому невозможно сопоставить достигнутые результаты с произведенными расходами ресурсов, т. е. оценить эффективность проведенных мероприятии с участием государства.

Из-за нерешенности данной проблемы усилия правительства по внедрению механизмов стратегического планирования на уровне министерств и ведомств ожидаемых результатов не дали.

Из года в год количество разрабатываемых программ увеличивались в виду того, что они являлись основными инструментами реализации стратегических планов государства. Когда правительство страны заявило о переходе на новые инструменты реализации стратегических планов государства, в стране действовали более 120 государственных, отраслевых (секторальных) программ и более 370 региональных программ. В соответствие с новой Концепцией 2007 года действия почти всех названных программ были приостановлены. Основным инструментом качественной реализации стратегических приоритетов страны отныне должны были стать вновь разрабатываемые стратегические планы министерств и ведомств. Они же должны были определять основные принципы распределения бюджетных средств по приоритетам государственной политики, а также обеспечить эффективность и прозрачность их расходования.

Однако, в ходе практического внедрения новых инструментов планирования были допущены серьезные методологические промахи, из-за чего стратегические планы министерств и ведомств не сумели стать основными инструментами реализации долго- и среднесрочных планов страны, с одной стороны, а с другой, так и не сумели стать основным документом формирования бюджета ведомства.

Вместе с тем, несмотря на наличие проблемных вопросов, анализ результатов оценки за 2 года свидетельствует о позитивных изменениях в сфере стратегического планирования. 
При этом, действующая модель системы оценки стратегических планов государственных органов в большей степени ориентирована на выявление несоответствий в работе госоргана установленным стандартам, правилам, требованиям.

При оценке достижения стратегических целей и задач приводятся лишь результаты расчета степени их достижения без анализа причин недостижения, правильности постановки целей и задач, а также мер, направленных на их реализацию.

Анализ показал, что почти все стратегические планы ведомств на сегодня содержат такие целевые индикаторы, значения которых от усилий ведомства не зависят и более того, как правило, в бюджете ведомства на улучшение значения целевых показателей не предусматриваются необходимые финансовые средства. Как показывает опыт других стран, в подобной ситуации стратегические планы ведомств как инструмент реализации стратегических приоритетов страны путем эффективного расходования бюджетных средств перестают выполнять свой основные функций.

По данным Министерства экономики и бюджетного планирования Республики Казахстан в 2012 году проведена оценка эффективности деятельности 23 центральных государственных и 16 местных исполнительных органов по направлению «Достижение и реализация стратегических целей и задач в курируемых отрасли/сфере/регионе» по итогам 2011 года.

Проведенный анализ результатов оценки стратегических планов государственных органов показали следующую картину. Так, в 2011 году оцениваемыми государственными органами реализовывалось 2076 целей и задач, закрепленных в 23 стратегических планах и 16 программах развития территорий. Работа госорганов была оценена как средняя эффективность [15].

Государственные органы Республики Казахстан работают на основе своих стратегических планов и должны нести прямую ответственность за достижение конкретных показателей и индикаторов, которые должны быть связаны с целями основных документов страны - Стратегии - 2030, Стратегического плана до 2020 года, государственных программ. При этом сами индикаторы стратегических планов ведомств должны быть сформулированы таким образом, чтобы с их помощью можно было бы отслеживать текущую деятельность ведомства по рациональному и результативному использованию ограниченных ресурсов государства, выделяемые на реализацию приоритетных задач страны. Следовательно, определение приоритетов развития отрасли и выделение на их реализацию государственных бюджетных ресурсов является первичным, а составление ключевых целевых индикаторов с их численными значениями - вторичный характер. Таким образом, текущему контролю и мониторингу при помощи целевых индикаторов должны подвергаться только такие действия ведомства, которые подкреплены реальными бюджетными ресурсами.

Данный подход станет принципиальным отличием от ранее действовавших подходов. Проведенный анализ, показал, что большинство из них оставались 
программами только на бумаге, без бюджетных ресурсов и очень часто без четкого понимания, каким стратегическим приоритетам они служат. Так, внедренных стратегических планов - 43, в них содержится более 2000 показателей. Большинство показателей не отражают реальную картину деятельности государственных органов, при этом госорганы включают свои не самые приоритетные вопросы в стратегические планы и, соответственно, они, как правило, неподкреплены бюджетными средствами. Такие действия делают бесполезными усилия Правительства по внедрению стратегических планов ведомств. Ведомства и их стратегические планы должны быть сфокусированы исключительно на самых важных и приоритетных задачах развития Казахстана, которые отражены в Стратегии-2030, Стратегическом плане до 2020 и должны быть подкреплены бюджетными ресурсами, а сами индикаторы стратегических планов ведомств - простыми, понятными, легко проверяемыми, достижимыми.

Вместе с тем, проблемы обеспечения качества стратегических планов и контроля не решены:

- не сформированы ключевые показатели эффективности, ориентированные на потребности населения.

Многие планы стратегических планов устанавливаются по принципу формального соответствия индикаторам вышестоящим документам системы государственного планирования без ориентации на потребности населения, а также подкрепления полномочиями и необходимыми ресурсами. Это приводит к размыванию ответственности за конечные результаты и не обеспечивают соответствующей отдачи для населения и бизнеса.

- не внедрены эффективные инструменты достижения показателей.

В государственных органах отсутствуют действенные механизмы превентивного контроля стратегических планов и программ: при высоком освоении средств практически каждая 5-я бюджетная программа оцениваемых государственных органов имела низкие результаты достижения показателей.

- отсутствует полноценная внешняя оценка стратегических планов.

- сохраняется слабая взаимосвязь между стратегическим и бюджетным планированием. В итоге, в конце каждого года государственные органы рапортуют о практически полном освоении бюджетных средств, тогда как степень достижения стратегических целей и задач остается на уровне $70-80 \%$.

В 2011 году при высоком освоении средств практически каждая 5-я бюджетная программа оцениваемых центральных госорганов имела низкие результаты достижения показателей.

В-пятых, недостаточно эффективно взаимодействие между центральными государственными и местными исполнительными органами.

Центральные государственные органы заинтересованы в максимальном отражении своих показателей в программах развития территорий. В итоге ряд показателей Программ развития территории не имеют методик по расчету фактических значений показателей либо рассчитываются только в масштабах респуб- 
лики, но не региона. Все это значительно затрудняет процесс мониторинга и оценки данных программ и чтобы определить, удалось ли государственному органу в результате реализации стратегического плана достичь поставленных целей и задач, необходимо разработать систему показателей [15].

Таким образом, для совершенствования методики формирования стратегических планов, необходимо усилить координацию государственных органов, тщательно подходить к определению промежуточных показателей и индикаторов.

Появление стратегических планов министерств и ведомств, прежде всего, было обусловлено необходимостью повышения персональной ответственности первых руководителей ведомств обществом по решению проблем рационального использования ограниченных ресурсов общества для достижения высоких конечных результатов.

Оценка эффективности использования бюджетных ресурсов, являющаяся основой БОР, на практике оказывается не простой задачей, так как результаты успешно проведенной той или иной государственной политики не всегда можно увидеть сразу, в течение планового периода. Несмотря на подобные трудности бюджетирование, ориентированное на результат в целом способствует эффективному и результативному использованию государственных средств, повышению бюджетной дисциплины, хотя является сложным и длительным процессом.

Таким образом, на сегодняшнем этапе внедрение стратегического планирования в стране пока не в полной мере способствовало достижению высоких результатов в использовании и распределении ограниченных ресурсов государства, прежде всего в рациональном использовании бюджетных средств. Необходимо разработать новые подходы по совершенствованию системы оценки стратегических планов государственных органов Республики Казахстан, которые позволили бы повысить качество документов Системы государственного планирования, оптимизировать их количество, усилить гибкость в принимаемых государственными органами решениях, ориентировать деятельность государственных органов на достижение конкретных результатов.

\section{Заключение}

1. В настоящее время в Казахстане сформирована институциональная база системы государственного планирования. Однако на практике имеют место проблемы по взаимоувязке целей и задач государственных органов с бюджетированием, обеспечения полной декомпозиции показателей и другие. Для решения этих и других проблем на системной основе проводится исследования и необходимо их продолжать.

2. В зарубежных странах, где внедрено бюджетирование, ориентированное на результаты, оценка реализации стратегических планов проводится ежегодно после утверждения окончательного варианта стратегических планов. В некоторых 
странах проводится также оценка по состоянию на середину года (промежуточная оценка). Однако во всех странах возможность проведения такой оценки появляется только после внедрения современных методов финансового менеджмента, включая соответствующее программное обеспечение.

3. Для достижения целей по модернизации управления, ориентированного на результат, в рамках системы государственного планирования необходимо обеспечение:

- создания и внедрения комплексной системы ведомственного и межведомственного планирования и проектного управления по целям и результатам деятельности;

- конкурентного распределения ресурсов между государственными органами и контроль за достижением результатов их деятельности;

- разработки ключевых измеримых показателей эффективности и результативности деятельности субъектов государственного планирования в соответствии со стратегическими целями государства;

- внедрения технологий и процедур целеполагания, обеспечивающих привязку целей к конкретным исполнителям;

- разработки показателей, позволяющих адекватно оценить степень достижения поставленных целей и действия исполнителей, предпринимаемые для достижения этих целей.

4. Целесообразно, осуществлять оценку не процессов, совершаемых государственным органом, а собственно конечный результат его деятельности при реализации и достижении стратегических целей и задач. Для выявления рисков недостижения запланированных результатов в государственных органах на первом этапе необходимо внедрить систему мониторинга программ/деятельности.

\section{Литература}

1. Система государственного планирования в Республике Казахстан. Коллектив авторов: АО «Институт экономических исследований»; ЧУ «Центр исследований прикладной экономики», 2013 г.

2. Paul Miesing, David F. Andersen . The Size and Scope of Strategic Planning in State Agencies: The New York Experience. The State University of New York, Albany. The American Review of Public Administration, June 1991 vol. 21 no. 2 119-137.

3. Isaiah O. Ugboro, Kofi Obeng, Ora Spann. Strategic Planning As an Effective Tool of Strategic Management in Public Sector Organizations. Evidence From Public Transit Organizations. Administration \& Society, January 2011, vol. 43 no. 1 87-123.

4. Theodore H. Poister. The Future of Strategic Planning in the Public Sector: Linking Strategic Management and Performance. Georgia State University. Public Administration Review. December 2010. Special Issue 246-254.

5. Barzelay, Michael, and Colin Campbell. 2003. Preparing for the Future: Strategic Planning in the U.S. Air Force. Washington, DC: Brookings Institution Press. 
6. Bryson, John M. 2004. Strategic Planning for Public and Nonprofit Organizations. 3rd ed. San Francisco: Jossey-Bass.

7. Bryson, John M., Barbara C. Crosby, and John K. Bryson. 2009. Understanding Strategic Planning and the Formulation and Implementation of Strategic Plans as a Way of Knowing: The Contributions of Actor-Network Theory. International Public Management Journal 12(2): 172-207.

8. Frentzel, William Y., John M. Bryson, and Barbara C. Crosby. 2000. Strategic Planning in the Military: Th e U.S. Naval Security Group Changes Its Strategy, 1992-1998. Long Range Planning 33(3): 402-429.

9. Мескон М. Х., Альберт М., Хедоури Ф. Основы менеджмента: Пер. с англ. - М.: Дело, 2002. $578 \mathrm{c}$.

10. Сенаторов А. Я. Японская модель самоуправления. Знакомьтесь - Япония. 2004. №11. с. 15

11. Динкевич А.И. Экономическое развитие современной Японии . Деньги и кредит. 2006. №10. С. 62-74.

12. Аткина Н.А., Ханжина В. Л., Попов Е. В. Менеджмент в России и за рубежом. 2003. №2

13. Указ Президента РК «О системе ежегодной оценки эффективности деятельности центральных государственных и местных исполнительных органов областей, города республиканского значения, столицы» от 19 марта 2010 года № 954.

14. Приказ Министра экономического развития и торговли Республики Казахстан от 19 января 2012 года № 14 «Об утверждении Методики по оценке эффективности достижения и реализации стратегических целей и задач в курируемых отрасли/сфере/регионе».

15. Рубашина И. Р. Разработка показателей результатов: что измеряем и зачем? Государственные финансы. № 9 (21), сентябрь 2012.

Gulsara Junusbekova

\section{Valstybės planavimo sistemos reforma Kazachstano Respublikoje*}

\section{Anotacija}

Straipsnyje nagrinejjama Kazachstano Respublikos valstybinio planavimo sistemos reformos patirtis. Svarstomos valstybės strateginio planavimo sisteminès problemos. Šiuo metu Kazachstane įdiegta institucinė valstybès planavimo sistemos struktūra. Tačiau praktikoje kyla problemų dèl ryšio tarp valstybės institucijų tikslų ir uždavinių darnos planuojant biudžetą, rodiklių sklaidos ir kt. Siekis spręsti šiuos ir kitus klausimus sistemingai rodo mokslinių tyrimų šioje srityje poreikị.

* Pranešimas šio straipsnio tema buvo pateiktas elektroninėje konferencijoje „Viešasis administravimas centrinejje Europoje: tradicijos paieškos“, organizuotoje Mykolo Romerio universiteto Viešojo administravimo instituto kartu su Akademine vadybos ir administravimo asociacija (AVADA) 2013 m. lapkričio 6-7 dienomis. 


\section{Gulsara Junusbekova}

\section{The Reform of the System of State Planning in the Republic of Kazakhstan}

Abstract

The experience of reforming the system of state planning in the Republic of Kazakhstan is examined in the article. The author considers a number of systemic problems in the state strategic planning. Currently, Kazakhstan has an institutional framework of the system of state planning. However, in practice, there are problems on the coherence between the objectives and tasks of state bodies with budgeting, full decomposition of indicators and others. To address these and other issues in a systematic manner, a need for research in this area is suggested.

Gulsara Junusbekova - Valstybinio valdymo akademijos prie Kazachstano Respublikos Prezidentūros Akademinių programų registro vadovė, docentė, ekonomikos mokslų daktarè, Astana, Kazachstanas.

E. paštas: gulsara_zhunus@mail.ru

Gulsara Junusbekova, PhD in Economics, Academy of Public Administration under the President of the Republic of Kazakhstan, Head of the Sector of Monitoring and Evaluation, Associate Professor.

E-mail: gulsara_zhunus@mail.ru

Straipsnis ịteiktas redakcijai 2013 m. spalio 10 d.; recenzuotas; parengtas spaudai $2013 \mathrm{~m}$. spalio mèn. 